\title{
O Ensino do Pensamento Computacional nas séries iniciais do Ensino Fundamental: investigando a percepção docente
}

\author{
Danilo Silveira Martins ${ }^{1}$, Francine da C. Queiroz Mota ${ }^{1}$, \\ Marlenice Guedes Rocha ${ }^{1}$, Caroline Queiroz Santos ${ }^{1}$, \\ Maria Lúcia Bento Villela ${ }^{1}$
}

\author{
${ }^{1}$ Programa de Mestrado em Educação - PPGed \\ Universidade Federal dos Vales do Jequitinhonha e Mucuri (UFVJM) \\ Diamantina - MG - Brasil \\ \{danilo.silveira, francine.mota, marlenice.guedes, \\ caroline.queiroz, maria.villela\}@ufvjm.edu.br
}

\begin{abstract}
This paper describes an exploratory research with a qualitative approach, conducted with elementary school teachers, which consisted of workshops on the teaching of Computational Thinking (CT). Through the application of questionnaires, the perceptions of teachers about the possibilities of teaching CT in the early grades were investigated. The results show that the teachers had already worked with CT concepts, although not in an intentional and systematized way. At the end of the workshops, they showed to be more confident and willing to introduce CT in the classroom. We recommend that similar training actions be developed, helping to spread the importance of the development of CT, regardless of the teaching level or the subject taught.
\end{abstract}

Resumo. Este artigo descreve uma pesquisa de cunho exploratório e abordagem qualitativa, realizada com professores do ensino fundamental, que consistiu na realização de oficinas sobre o ensino do Pensamento Computacional (PC). Por meio da aplicação de questionários, investigou-se as percepções docentes acerca das possibilidades de ensino do PC nas séries iniciais. Os resultados apontam que os conceitos de PC já eram trabalhados pelos docentes, embora de forma não intencional e sistematizada. Ao final das oficinas, eles mostraram-se mais seguros e predispostos a introduzir o PC em sala de aula. Recomendamos que ações de formação similares sejam desenvolvidas, contribuindo para propagar a importância do desenvolvimento do PC, independentemente do nível de ensino ou da disciplina ministrada.

\section{Introdução}

O Pensamento Computacional (PC) vem sendo amplamente discutido como necessário aos cidadãos do século XXI para solucionar problemas de forma mais eficiente, empregando habilidades como a abstração, o raciocínio lógico, reconhecimento de padrões, entre outros [Ribeiro et al. 2019]. Ao adotar o PC em seus processos de resolução de problemas, muitas áreas do conhecimento podem se beneficiar [Wing 2006], tendo em vista que o PC estimula a criação de soluções eficazes e úteis. Por isso, este deveria ser desenvolvido desde a educação básica, desafiando os estudantes a pensarem computacionalmente na resolução de seus problemas e tornando, assim, o "pensamento computacional um lugar comum" [Wing 2006, p.35. Tradução nossa]. 
A inserção do PC na educação precisa ser pensada pedagógica e epistemologicamente, pois é necessário ter atenção sobre as diferentes e mais adequadas metodologias e instrumentos que podem ser usados para este fim [Kaminski et al. 2021]. Com isso, para que o ensino do PC seja uma realidade nas escolas brasileiras, será preciso vencer alguns desafios, sendo a formação docente um dos principais [França e Tedesco 2015]. A motivação para este trabalho surgiu durante a realização de um trabalho na disciplina optativa sobre pensamento computacional do Programa de Pós-graduação em Educação da Universidade Federal dos Vales do Jequitinhonha e Mucuri (PPGed/UFVJM), em que os discentes foram convidados a refletirem sobre o assunto e realizarem atividades práticas sobre a temática.

Assim, propusemos uma investigação para entender a percepção de professores do ensino fundamental sobre o PC. A questão norteadora do estudo foi: "Quais as percepções docentes acerca das possibilidades do ensino do pensamento computacional nas séries iniciais do Ensino Fundamental?" Para tentar responder a esta questão, desenvolvemos oficinas teórico-práticas com professores de uma escola municipal. Nas oficinas, buscamos coletar as percepções prévias dos docentes sobre a temática e, após as atividades previstas, verificamos se houve mudanças nas percepções em relação à possibilidade de adoção do ensino do PC em sala de aula.

Este artigo está assim organizado: na seção 2 apresentamos os trabalhos relacionados, cujas pesquisas se referem a percepções de professores do Ensino Fundamental sobre o PC; na seção 3, apresentamos e descrevemos a metodologia; na seção 4 apresentamos e discutimos os resultados e, por fim, na seção 5, as considerações finais.

\section{Trabalhos Relacionados}

Nesta seção, apresentaremos estudos que pesquisaram as percepções de professores do Ensino Fundamental sobre o pensamento computacional, por meio de ações de formação docente relacionadas à temática, semelhantes ao que propomos nesta pesquisa.

[Silva et al. 2017] apresentam os resultados de um projeto de formação docente para professores da educação básica. O objetivo foi a divulgação do PC como ciência interdisciplinar, mediante a apresentação de seu conceito e das possibilidades de aplicação em sala de aula, por meio da computação desplugada, do LightBot e do Scratch. Os autores apontam um desinteresse inicial dos docentes em relação ao PC, que pode estar associado ao desconhecimento do tema. Apesar disso, os resultados demonstram uma ampliação da percepção dos professores sobre o PC em um enfoque interdisciplinar. Eles vislumbraram a possibilidade de aplicação das atividades na sala de aula, além de se sentirem motivados a multiplicar os conhecimentos adquiridos em suas escolas.

[Júnior e Oliveira 2019] realizaram uma oficina introdutória sobre PC com professores da rede municipal. Eles observaram que a totalidade dos professores desconhecia o conceito de PC e não teve oportunidade de participar anteriormente de nenhuma ação de formação sobre o tema. O estudo assinalou que mesmo diante de uma oficina de curta duração, é possível uma mudança promissora no entendimento conceitual de PC e no reconhecimento de sua importância em sala de aula. Os autores apontam a possibilidade de exploração da interdisciplinaridade na aplicação dos conceitos de PC e propõem o desenvolvimento da metodologia de projetos para esse fim.

[Santos et al. 2016] realizaram uma oficina teórico-prática com professores da 
Educação Infantil, na qual trabalharam alguns conceitos de PC (algoritmos, sequenciação e depuração) por meio da computação desplugada. Os resultados demonstraram que poucos professores tinham conhecimento ou tiveram oportunidades de formação nessas temáticas. Além disso, alguns deles apontaram que já trabalhavam conceitos similares ao de sequência e depuração, porém sem o uso da tecnologia. Os autores observaram certa resistência docente em trabalhar assuntos relacionados à tecnologia, por não se julgarem preparados. Em razão disso, delegavam essa responsabilidade aos professores de informática. Para os autores, essa tendência prejudica a disseminação do ensino do PC nas escolas brasileiras, já que grande parte delas não contam com profissionais especializados em tecnologia ou com disciplinas específicas de Informática em seu currículo.

O trabalho de [Silva et al. 2014] apresenta a iniciativa de oferta de oficinas para professores das redes estadual e municipal de ensino, nas quais foram realizadas atividades plugadas, com o uso do software Scratch, e atividades lúdicas com o uso da computação desplugada. Os professores apontaram a importância dessa iniciativa de formação, manifestando interesse pela continuidade dos encontros para aprofundar as possibilidades de aplicação. Dentre as dificuldades apontadas pelos docentes, destacamse a curta duração das oficinas e, por parte de alguns deles, foram relatadas dificuldades com o uso do computador no nível de informática básica.

[Lira et al. 2019] realizaram a oficina "Desenvolvendo recursos digitais com o Scratch" com o objetivo de criar Recursos Educacionais Digitais (RED) para construção de conceitos matemáticos apoiados no uso das tecnologias digitais. Como resultado, foi apontada pelos participantes a importância da contínua formação para atendimento das necessidades contemporâneas do ensino. Os autores destacam, dentre as contribuições da pesquisa, uma maior apropriação tecnológica pelos docentes, o que contribui para o seu letramento digital e maior "empoderamento", uma vez que puderam perceber a autoria dos seus próprios REDs como uma possibilidade real.

Um curso de maior duração (6 meses) para professores de Matemática e Informática do Ensino Fundamental é apresentado no trabalho de [Barros et al. 2018], no qual utilizaram o Scratch para abordar 7 dimensões do PC: abstração e decomposição de problemas, pensamento lógico, sincronização, paralelismo, noção logarítmica de controle de fluxo, interação com usuário e representação de dados. Além de participarem das oficinas, os professores contaram com um apoio online para o desenvolvimento das atividades com seus alunos. Os autores identificaram uma certa resistência por parte dos professores em integrar o ensino do PC à sua prática docente, especialmente entre os professores de Matemática. Essa resistência foi tida como uma questão problemática, uma vez que todas as menções ao PC na Base Nacional Comum Curricular (BNCC) ocorrem na referida disciplina. Além disso, para a disseminação do ensino de PC na Educação Básica, os autores pontuam a importância da adesão e do apoio dos professores.

[Kologeski et al. 2016] desenvolveram oficinas com os docentes por meio do Projeto Logicando, com o objetivo de desenvolver o raciocínio lógico apoiado pelas TDICs, no âmbito das ciências exatas. Além do estudo dos temas "Raciocínio lógico" e "Lógica de Programação", nesses encontros eram elaborados planos de ensino para posterior desenvolvimento pelos docentes. Os autores relatam um retorno muito positivo, tanto por parte dos professores quanto dos alunos em vários aspectos, como: $i$ ) maior motivação discente, ii) maior percepção docente de que as atividades contribuem para o desenvolvi- 
mento do raciocínio lógico, e iii) ampliação do saber fazer docente no tocante às metodologias de ensino apoiadas por ferramentas digitais.

Nosso estudo se diferencia dos demais supracitados pelo contexto de realização. Ele foi realizado no período de isolamento social devido a pandemia de COVID-19, em que os meios digitais colocaram-se como única alternativa para realização dos encontros de formação. Assim, todas as atividades práticas, mesmo aquelas denominadas "desplugadas", precisaram de adaptações para que pudessem ser desenvolvidas por meio de reuniões por videoconferência. Essas adaptações serão detalhadas na próxima seção.

\section{Metodologia}

Esse trabalho consiste em um estudo de caso e caracteriza-se por ser uma pesquisa de cunho exploratório, com abordagem qualitativa. Objetivando investigar a percepção docente sobre as possibilidades do ensino do PC nas séries iniciais do Ensino Fundamental, três oficinas foram realizadas, cada uma com 2 horas de duração, nos meses de maio e junho de 2021. Os participantes eram professores das séries iniciais do Ensino Fundamental de uma escola da rede municipal de Pirapora, estado de Minas Gerais. As oficinas foram realizadas por meio de videoconferências no Google Meet, tendo em vista as necessidades de isolamento social impostas pela pandemia de Covid-19. O Google Sala de Aula foi utilizado como repositório de materiais e comunicação com os participantes durante as oficinas.

Participaram da pesquisa 12 docentes da educação básica (séries iniciais do Ensino Fundamental), com apenas um participante do sexo masculino, conforme apresentado na Tabela 1. No decorrer das oficinas, os professores responderam a dois questionários por meio do Google Forms. O primeiro, aplicado no início da $1^{\mathrm{a}}$ oficina, verificou a compreensão conceitual do $\mathrm{PC}$ e as percepções docentes acerca da temática proposta. $\mathrm{O}$ segundo, aplicado ao final da última oficina, com os participantes mais familiarizados com conceitos e práticas de PC, buscou verificar mudanças de percepções, bem como a predisposição dos professores no sentido de incluírem o PC em suas aulas.

\subsection{Desenvolvimento das atividades}

O planejamento e desenvolvimento das oficinas foi baseado no Currículo de Referência em Tecnologia e Computação do Centro de Inovação para a Educação Brasileira (CIEB), que em sua organização estabelece um diálogo com as competências e habilidades previstas na BNCC [CIEB 2021]. Essa proposta curricular possui três eixos que perpassam as diversas etapas da educação básica: i) Cultura Digital; ii) Tecnologia Digital e iii) Pensamento Computacional. As oficinas abordaram esses três eixos, porém as atividades práticas centraram-se no eixo "Pensamento Computacional". Essa delimitação se justifica pela importância e necessidade do ensino do PC, que é considerado "um dos pilares fundamentais do intelecto humano, junto a leitura e a aritmética" [CIEB 2021, n.p.].

O PC pode ser ensinado sem o uso de computadores, o que é chamado de "computação desplugada", com as atividades sendo realizadas de forma cinestésica como "movimentar-se, usar cartões, recortar, dobrar, colar, desenhar, pintar, resolver enigmas, etc.” [Brackman 2017, p. 50]. As atividades desplugadas não conferem uma abordagem plena dos conceitos de computação. Por isso, é mister a utilização de atividades de "computação plugada", que, como o nome indica, requer o uso de computadores. 


\begin{tabular}{l|c|l|l|c}
\hline ID & Faixa etária & Sexo & Formação & $\begin{array}{l}\text { Possui } \\
\text { especialização } \\
\text { Lato Sensu? }\end{array}$ \\
\hline P1 & 31 a 40 & F & Pedagogia & Não \\
\hline P2 & 21 a 30 & F & $\begin{array}{l}\text { Metodologia e Didática } \\
\text { do Ensino Superior }\end{array}$ & Sim \\
\hline P3 & 41 a 50 & F & Psicopedagogia & Sim \\
\hline P4 & 51 a 60 & F & Psicopedagogia & Sim \\
\hline P5 & 41 a 50 & F & $\begin{array}{l}\text { Orientação, supervisão } \\
\text { e inspeção escolar }\end{array}$ & Sim \\
\hline P6 & 41 a 50 & F & Pedagogia & Não \\
\hline P7 & 41 a 50 & F & Normal Superior & Sim \\
\hline P8 & 41 a 50 & F & $\begin{array}{l}\text { Normal Superior } \\
\text { e Letras/Português }\end{array}$ & Sim \\
\hline P9 & Acima de 60 & M & Letras, Pedagogia & Sim \\
\hline P10 & 41 a 50 & F & Normal Superior & Não \\
\hline P11 & 41 a 50 & F & Pedagogia & Sim \\
\hline P12 & 41 a 50 & F & Pedagogia & Sim \\
\hline
\end{tabular}

Tabela 1. Perfil dos participantes

Para explorar os conceitos de PC, apresentamos aos participantes a parte teórica, por meio de um tour pelo site do CIEB ${ }^{1}$, expondo as possibilidades de navegação pelo Currículo de Referência em Tecnologia e Computação. Exploramos o currículo, suas especificidades e possibilidades de orientação às escolas e aos professores que tenham interesse de introduzir o PC nos currículos escolares. Na sequência, discutimos as seguintes habilidades do PC, previstas no currículo do CIEB:

- Decomposição: quebra de um problema complexo em partes menores e fáceis de manusear [Liukas 2015];

- Reconhecimento de padrões: busca de similaridades ou problemas parecidos que já foram solucionados [Brackman 2017]; [Ribeiro et al. 2019].

- Abstração: foco nos detalhes importantes, ignorando informações irrelevantes [Brackman 2017];

- Algoritmos: organização de passos para resolver um problema ou atingir um objetivo [Andrade et al. 2013].

Após a exploração teórica da temática, foram desenvolvidas atividades práticas plugadas e desplugadas. As atividades desplugadas foram baseadas nas sugeridas pelos sites Pensamento Computacional ${ }^{2}$ e Computação Desplugada ${ }^{3}$, com adaptações para realização de forma remota e online. A atividade plugada foi uma das atividades do projeto "A Hora do Código" ${ }^{4}$, que também foi planejada para o contexto remoto e online.

\subsubsection{Atividades desplugadas}

Foram desenvolvidas duas atividades desplugadas durante as oficinas: $i$ ) Decomposição com a turma da Mônica e ii) Bugs. Essas atividades tiveram o objetivo de demonstrar as

\footnotetext{
${ }^{1}$ Disponível em:https: / / curriculo.cieb.net.br/curriculo

${ }^{2}$ Disponível em: https: / / www. computacional.com.br/

${ }^{3}$ Disponível em: http://desplugada.ime.uni camp.br/atividades.html

${ }^{4}$ Disponível em: http: / / code.org
} 
possibilidades de trabalho com os pilares da abstração, decomposição e algoritmos. Por meio de listas de instruções, os participantes puderam atingir objetivos comuns do diaa-dia, pela decomposição de problemas grandes em problemas menores e também pelo reconhecimento de equívocos na composição de diagramas e conjuntos de ações.

Ambas as atividades, se desenvolvidas no ensino presencial, requereriam apenas o uso de material impresso, lápis e borracha. No ambiente online, optamos pelas seguintes adaptações: para realização da primeira atividade, utilizamos o aplicativo Google Jamboard, de forma que os participantes trabalhassem simultaneamente, em duplas, para criação de um algoritmo que atingisse cada objetivo proposto. Já na segunda atividade utilizamos o aplicativo Lucidchart, que possibilitou a criação de diagramas de forma colaborativa, o que permitiu a correção dos bugs, nos diagramas, pelos participantes. Outras duas atividades (Figura 1) foram realizadas com base nas do site Computação Desplugada:

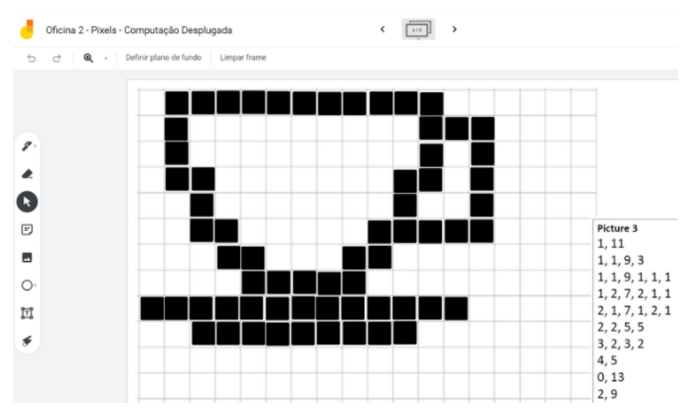

(a) Colorindo com números no Jamboard

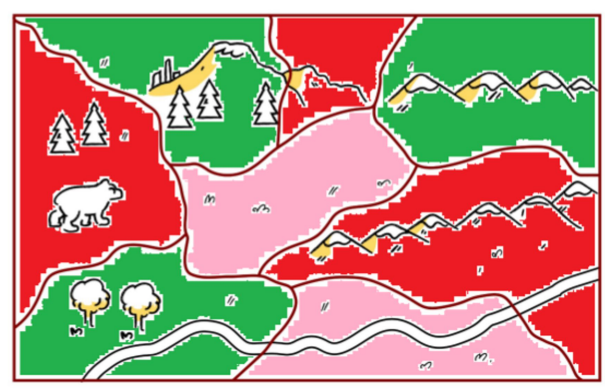

(b) Exemplo de um mapa pintado no Paint

Figura 1. Atividades desplugadas realizadas

$1^{\text {a) }}$ Colorindo com números - representação de imagens: possibilita uma interdisciplinaridade entre as disciplinas de arte, matemática e computação, à medida em que explora a representação de desenhos em malha quadriculada, mediante o uso de números e permitindo a exploração da ideia de compactação e compressão de imagens. Tal como a atividade $i$ ), descrita anteriormente, para a apresentação e desenvolvimento dessa atividade utilizamos o aplicativo Jamboard (Figura 1(a)) em substituição ao uso do papel e do lápis, que seriam utilizados em um cenário presencial. Com o uso do referido aplicativo, os participantes puderam trabalhar colaborativamente na composição das figuras.

$2^{\text {a) }}$ O cartógrafo pobre - colorindo mapas: possibilita o trabalho com o conceito de grafo, de forma interdisciplinar, nas disciplinas de História e Geografia. Permite a exploração de diversos mapas, com diferentes níveis de complexidade, abordando o problema das 4 cores. No meio digital, essa atividade foi desenvolvida por meio do envio dos arquivos digitais com os mapas. Os participantes abriram os mapas com o aplicativo Paint e fizeram as atividades propostas, que consistiam em pintar os países com o menor número possível de cores, garantindo que países vizinhos tivessem cores diferentes, conforme modelo representado na Figura 1(b).

\subsubsection{Atividade plugada}

Para a atividade plugada, trabalhamos o "Labirinto Clássico", da série de atividades Hora do Código, no site Code.org (Figura 2). Ela explora os conceitos básicos de programação 
com uso de blocos visuais que permitem a criação de um programa, além de técnicas simples de depuração. Na adaptação para o formato remoto, apresentamos as noções gerais da ferramenta, seguidas da demonstração das duas primeiras fases do desafio. Após os esclarecimentos iniciais, compartilhamos o link via chat do Google Meet e estipulamos o tempo de 2 minutos para realização de cada fase. À medida em que se esgotava o tempo, os participantes eram convidados à retornar ao Meet e solicitávamos a um deles a compartilhar sua tela e explicar como chegou à solução. Em cada fase eram discutidos os conceitos de programação envolvidos.

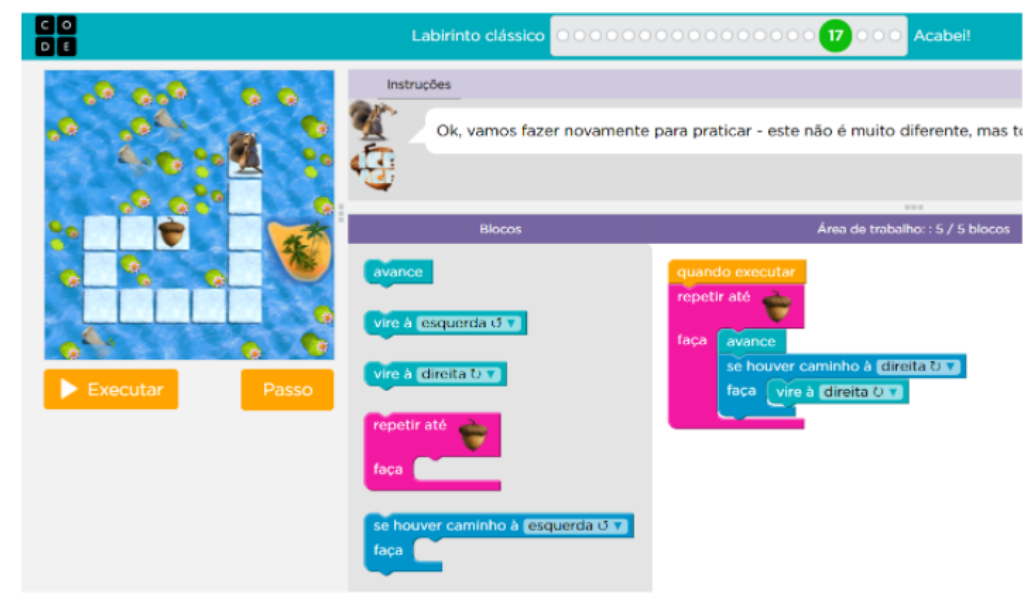

Figura 2. Print da tela da atividade Labirinto Clássico

\section{Resultados e Discussão}

Conforme abordado anteriormente, os professores responderam a dois questionários em momentos distintos: antes e após a realização das oficinas. As respostas dadas pelos professores ao $1^{\circ}$ questionário mostraram que mais da metade deles $(66,7 \%)$ não teve oportunidade de estudar o PC em sua formação inicial ou continuada. Além disso, 66,6\% relataram que nunca ou raramente trabalharam o ensino do PC com seus alunos, mas dois deles afirmaram trabalhar frequentemente.

Esses dados se aproximam dos estudos feitos por [Júnior e Oliveira 2019, Santos et al. 2016, França e Tedesco 2015, Valente 2016] que apontam que a falta de oportunidades de formação docente ainda se constitui em um desafio para o desenvolvimento do PC na educação básica. Apesar do crescimento dos estudos envolvendo o PC e a elevação da quantidade de pesquisas e produções científicas sobre o assunto, ele ainda não é devidamente reconhecido como ciência, desde os anos iniciais da educação básica [Fantinati e dos Santos Rosa 2021]. Além disso, os documentos curriculares nacionais não indicam, de forma clara e explícita, a introdução das habilidades do PC nesse nível de ensino, embora haja previsão de desenvolvimento de algumas delas, especificamente em Matemática. Nesse cenário, consideramos que iniciativas como a da Sociedade Brasileira de Computação (SBC) colaboram muito na construção de um currículo referencial para o $\mathrm{PC}$, em interface com a $\mathrm{BNCC}$, pois permite a reflexão das escolas sobre a sua adoção no currículo e em suas práticas [Brackman 2017].

Sobre não terem tido oportunidades de formação sobre o $\mathrm{PC}$, as respostas ao $1^{\circ}$ questionário apontam que $83,4 \%$ dos professores reconhecem a importância de trabalhar 
o PC junto aos alunos, sendo que, para $91,7 \%$ deles, isso contribui para o desenvolvimento do raciocínio lógico e agilidade na solução de problemas. Após as oficinas, essas percepções foram apontadas pela totalidade dos professores, que também assinalaram que, de alguma forma, já desenvolviam as habilidades do PC junto a seus alunos.

Perguntamos, também, aos professores, o quanto eles trabalhavam as habilidades do PC (decomposição, reconhecimento de padrões, abstração e algoritmo) em sua prática docente. As respostas estão representadas na Figura 3, sendo que na Figura 3(a) está a percepção prévia e, na Figura 3(b), a percepção pós oficinas.

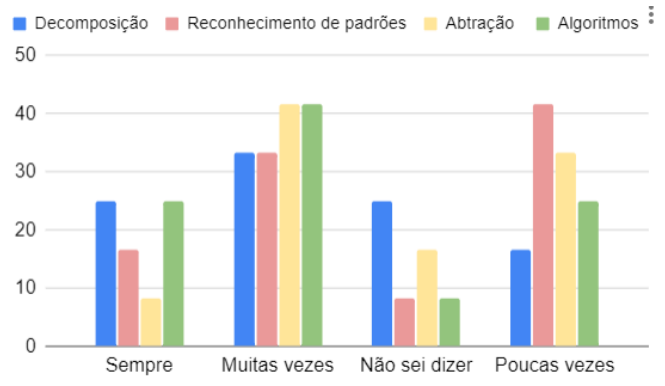

(a) Antes das oficinas

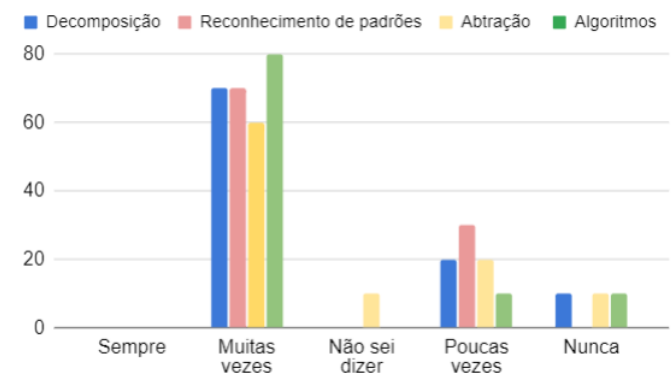

(b) Depois das oficinas

Figura 3. Percepção docente quanto à frequência com que são trabalhadas as habilidades do PC em sua prática

Percebemos uma mudança na percepção docente em relação ao trabalho com as habilidades mencionadas. Houve um reconhecimento de que já aplicavam os conceitos, embora de forma não intencional e reflexiva, o que fica implícito nos relatos ao final das oficinas: "Lembrando do diagnóstico inicial e no decorrer das oficinas, percebi que faço uso do pensamento computacional nas minhas práticas em sala de aula, e isso abriu mais o leque de conhecimento (P9)"; "Conhecimentos que temos e trabalhamos de maneira 'informal' e que faz tanta diferença (P4)."

Questionados sobre a possibilidade de interdisciplinaridade do ensino do PC nas disciplinas que ministram, tanto no $1^{\circ}$ quanto no $2^{\circ}$ questionário, $100 \%$ dos participantes responderam positivamente. No entanto, o grau de concordância sobre esse quesito aumentou de $16,7 \%$ para $50 \%$ após o desenvolvimento das oficinas, o que é um dado positivo. O desenvolvimento do PC de forma integrada com as disciplinas do currículo pode favorecer a sua disseminação, especialmente em um contexto em que inexista disciplinas específicas que abordem o PC no currículo escolar [França e Tedesco 2015]. A introdução do PC na educação básica precisa ser provida de uma intencionalidade, se pensando no porquê, no para quê e em como realizar essa introdução, distanciando-se da adoção apenas por modismos [Kaminski et al. 2021]. Os docentes precisam ter clareza, não apenas de questões técnicas, mas de como promover a integração com os diversos conteúdos e disciplinas do currículo.

Uma das possibilidades de introdução ao PC é a computação desplugada, que independe de disponibilização de computadores, o que pode ser bastante interessante, especialmente para escolas que não possuem laboratórios de informática ou dispositivos digitais para uso dos alunos. Mais da metade $(58,3 \%)$ dos participantes afirmou ser imprescindível a disponibilização do laboratório de informática para o ensino do PC. Entretanto, após as oficinas, esse percentual caiu para 20\%. Percebemos esse resultado como 
positivo pois, segundo [Wing 2006], a falta de equipamentos e de infraestrutura não devem ser usada como argumento para inviabilizar os trabalhos com PC. Os conceitos de PC devem servir, principalmente, à resolução de problemas, por meio do exercício do raciocínio e da criatividade.

Além das atividades desplugadas, o trabalho com o PC pode envolver atividades plugadas, que demandam a utilização de aplicativos, plataformas, jogos e sites. Nesse sentido, a pesquisa revelou que a despeito de todos os participantes concordarem com a importância do uso de softwares, a maioria $(83,4 \%)$ nunca utilizou $(16,7 \%)$ ou utiliza poucas vezes $(66,7 \%)$ tais recursos em sua prática pedagógica. Isso pode indicar que os professores possuem pouca familiaridade com as tecnologias em sua prática docente, $\mathrm{o}$ que pode dificultar a compreensão e o desenvolvimento do pensamento computacional.

Embora seja possível trabalhar alguns conceitos com a computação desplugada, para o ensino do PC é necessário que o professor se aproxime das tecnologias, em sua diversidade e complexidade, e se torne apto a refletir sobre possíveis aplicabilidades em sua disciplina, não apenas no aspecto instrumental, mas no que concerne a teorias e modelos que as embasem [Brackman 2017]. Além disso, [Lira et al. 2019] aponta a necessidade de tornar o ambiente escolar mais próximo da vivência social dos estudantes. O autor ressalta a intensidade com a qual as crianças convivem com as TDICs (navegar, postar fotos, dentre outras atividades), enquanto isso, as práticas e rotinas escolares não aproveitam essas tecnologias e suas potencialidades pedagógicas.

Mesmo que as escolas e os docentes tenham baixa adoção de tecnologias, várias habilidades do PC podem ser desenvolvidas com os alunos [CIEB 2021]. Mais da metade dos participantes discordou que seja necessário uma formação específica em Computação para ensinar o PC. Após as oficinas, esse índice aumentou. Isso mostra que os professores compreenderam que não precisam ser especialistas em tecnologias ou computação para trabalhar o PC. [Kaminski et al. 2021] pontua que, para a inserção do PC nas escolas, é preciso que haja colaboração entre os especialistas ou estudiosos de TDICs e os professores, que são quem, de fato, as utilizarão nas suas práticas. Para os autores, os movimentos de inserção das TDICs nas escolas não pode desconsiderar a atuação do professor como mediador da aprendizagem.

Por fim, mesmo diante de oficinas de curta duração, os professores participantes deste estudo se tornaram mais conscientes e predispostos a introduzirem o PC em sua prática, independente das iniciativas de instâncias superiores (Figura 4). Observamos que, a partir das oficinas, o nível de segurança para o trabalho com os conceitos do PC aumentou. Em uma escala, em que 0 (zero) corresponde a completamente inseguro e 5 a suficientemente seguro, $60 \%$ dos participantes afirmaram estar seguros ou suficientemente seguros para implementação dos conceitos de PC em sua prática pedagógica.

\section{Considerações finais}

Compreendendo que o ensino do Pensamento Computacional ainda está em fase embrionária [França e Tedesco 2015], neste estudo reforçamos a necessidade de realização de pesquisas e iniciativas de formação docente para maior disseminação do PC na educação. Acreditamos que o PC estimula o desenvolvimento do raciocínio lógico, da argumentação, do posicionamento crítico, da abstração, entre outras habilidades.

Percebemos que os participantes deste estudo já desenvolviam algumas habilida- 


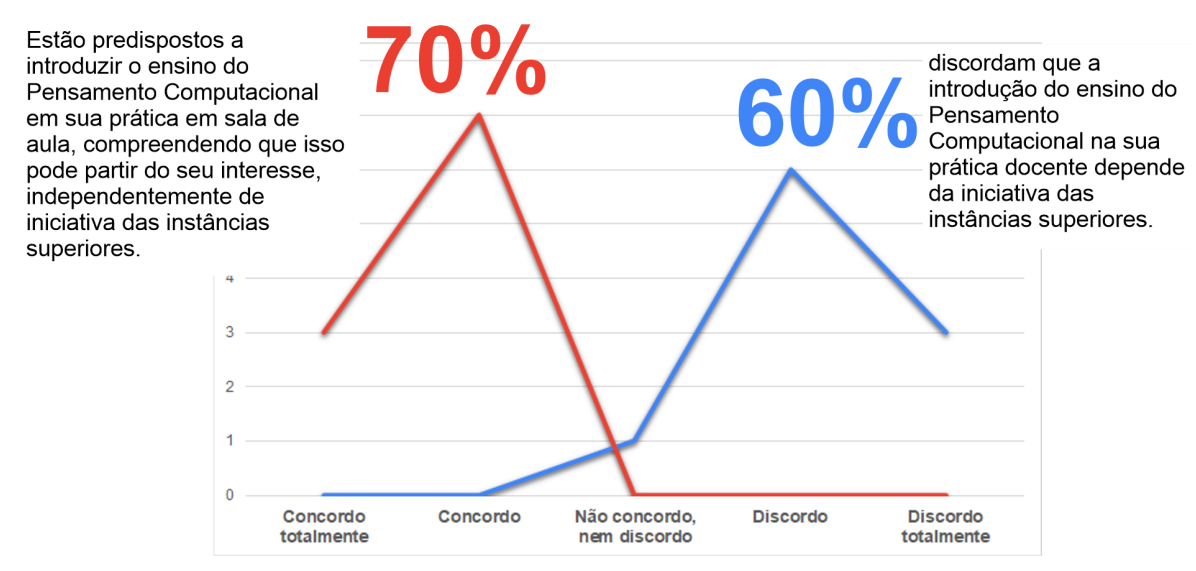

Figura 4. Respostas dos participantes sobre predisposição para adoção do PC em sala de aula

des de PC em suas práticas, ainda que de forma não intencional e não reflexiva. Isso nos permitiu constatar que o conceito de PC ainda não é conhecido e nem disseminado entre educadores. A partir das oficinas, eles reconheceram as possibilidades e benefícios da aplicação do PC em sua prática, no contexto da resolução de problemas. Essa compreensão, conforme [Ramos e Espadeiro 2014] abre possibilidades ao professor, no sentido de traçar novas estratégias didático-metodológicas dentro de sua própria disciplina.

Por meio desse estudo, em que as oficinas podem ser consideradas uma proposta de ação de formação, compreendemos que é preciso que haja uma aproximação e articulação da academia com os professores da educação básica em seu contexto. Isso pode contribuir para a "evangelização" do PC, estimulando a propagação de seus conceitos e possibilidades de aplicação nas instituições educativas, independentemente do nível de ensino ou da disciplina ministrada.

Para caminhar nessa direção, concebemos a importância do conhecimento das realidades específicas e da realização de ações de formação docente, inclusive para uso de recursos tecnológicos, para realização de atividades plugadas com os estudantes. Tais ações corroboram para a disseminação do PC e para o estabelecimento de um ambiente cujas práticas pedagógicas sejam mais conscientes e intencionais, com previsão clara no currículo escolar, e adotadas de forma mais reflexiva pelos professores e por todos os envolvidos na construção das diretrizes curriculares. Ressaltamos, como ponto positivo do estudo, a abertura dos participantes no que tange ao trabalho com tecnologias e computação, além de uma predisposição a introduzirem o ensino do PC em sua prática docente. Em síntese, houve uma identificação com a temática proposta nas oficinas.

As limitações deste trabalho estão relacionadas ao contexto de pandemia de COVID-19, em que não pudemos realizar oficinas presenciais e também limitou a participação de um número maior de professores nas oficinas. Por ser um trabalho de uma disciplina de mestrado, também tivemos a limitação de tempo para planejar e executar o estudo. Como trabalhos futuros, acreditamos que a realização de ações de formação que investiguem a interdisciplinaridade do PC nas séries iniciais do ensino fundamental será uma boa contribuição. Além disso, a replicação deste estudo com professores de contextos variados pode auxiliar uma discussão mais aprofundada dos resultados. 


\section{Referências}

Andrade, D., Carvalho, T., Silveira, J., Cavalheiro, S., Foss, L., Fleischmann, A. M., Aguiar, M., and Reiser, R. (2013). Proposta de atividades para o desenvolvimento do pensamento computacional no ensino fundamental. In Anais do Workshop de Informática na Escola, volume 1, page 169.

Barros, T. T. T., Reategui, E. B., Meira, R. R., and Teixeira, A. C. (2018). Avaliando a formação de professores no contexto do pensamento computacional. RENOTE, 16(2):556-565.

Brackman, C. (2017). Desenvolvimento do pensamento computacional através de atividades desplugadas na educação básica. Master's thesis, 113f. Tese (Doutorado). Universidade Federal do Rio Grande do Sul (UFRGS). Porto Alegre - RS.

CIEB (2021). Currículo de referência em tecnologia e computação.

Fantinati, R. E. and dos Santos Rosa, S. (2021). Pensamento computacional: Habilidades, estratégias e desafios na educação básica. Informática na educação: teoria \& prática, 24(1 Jan/Abr).

França, R. and Tedesco, P. (2015). Desafios e oportunidades ao ensino do pensamento computacional na educação básica no brasil. In Anais dos Workshops do Congresso Brasileiro de Informática na Educação, volume 4, page 1464.

Júnior, P. A. P. and Oliveira, S. d. (2019). Pensamento computacional: uma proposta de oficina para a formação de professores. RENOTE, 17(1):62-71.

Kaminski, M. R., Klüber, T. E., and Boscarioli, C. (2021). Pensamento computacional na educação básica: Reflexões a partir do histórico da informática na educação brasileira. Revista Brasileira de Informática na Educação, 29:604-633.

Kologeski, A. L., Silva, C. G., Barbosa, D. N. F., Mattos, R. R., and Miorelli, S. T. (2016). Desenvolvendo o raciocínio lógico e o pensamento computacional: experiências no contexto do projeto logicando. RENOTE, 14(2).

Lira, A. d. S., Leitão, D. A., and Castro, J. B. d. (2019). Como o processo de produção de mídias pode contribuir para a formação docente? RENOTE, 17(1):425-434.

Liukas, L. (2015). Hello Ruby: adventures in coding, volume 1. Macmillan.

Ramos, J. L. and Espadeiro, R. G. (2014). Os futuros professores e os professores do futuro. os desafios da introdução ao pensamento computacional na escola, no currículo e na aprendizagem. EFT: Educação, Formação \& Tecnologias, 7(2):4-25.

Ribeiro, L., Foss, L., and da Costa Cavalheiro, S. A. (2019). Pensamento computacional: Fundamentos e integração na educação básica. Jornada de Atualização em Informática na Educação, 8(1):25-63.

Santos, E. R. d., Soares, G., Dal Bianco, G., da Rocha Filho, J. B., and Lahm, R. A. (2016). Estímulo ao pensamento computacional a partir da computação desplugada: uma proposta para educação infantil. Revista Latinoamericana de Tecnología Educativa.

Silva, T. R. d., Araujo, G. G. d., and Aranha, E. H. d. S. (2014). Oficinas itinerantes de scratch e computaçao desplugada para professores como apoio ao ensino de 
computaçao-um relato de experiência. In Anais do Workshop de Informática na Escola, volume 20, page 380 .

Silva, V., da Silva, L. L., and França, R. (2017). Pensamento computacional na formação de professores: experiências e desafios encontrados no ensino da computação em escolas públicas. In Anais do Workshop de Informática na Escola, volume 23, page 805 .

Valente, J. A. (2016). Integração do pensamento computacional no currículo da educação básica: diferentes estratégias usadas e questões de formação de professores e avaliação do aluno. Revista E-curriculum, 14(3):864-897.

Wing, J. M. (2006). Computational thinking. Communications of the ACM, 49(3):33-35. 